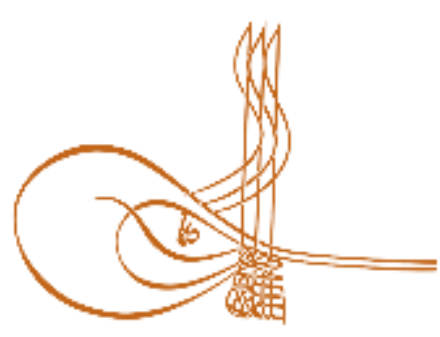

www.turkishstudies.net/social
Turkish Studies - Social Sciences

eISSN: $2667-5617$

Research Article / Araștırma Makalesi

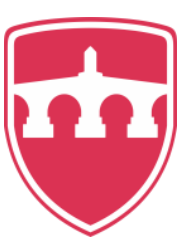

INTERNATIONAL

BALKAN

UNIVERSITY

Sponsored by IBU

\title{
Ailelerin Aşı Karşıtlığı Tutumlarının Hemşireler Tarafından Değerlendirilmesine Yönelik Nitel Bir Çalışma
}

\author{
A Qualtative Study on the Evaluation of the Attitudes of the Families Against Vaccination By \\ Nurses
}

Handan Ertaş ${ }^{*}$ - Ramazan Kıraç** - Seda Nur Ünal ${ }^{* * *}$

\begin{abstract}
In this study, it was aimed to evaluate nurses' reasons for being anti-vaccine, from which sources they area ffected, how they protect their children without vaccination, in short, the attitudes of patients against vaccination by nurses. In this study, qualitative research method and case science pattern were used. As a data collection tool, a semi-structured interview form was formed by using the related literatüre and expert opinions. Face to face interview technique was used in thestudy. The study was analyzed by the maticanalysis method. The study was conducted in three districts in Konya. These districts are Karatay, Meram and Seljuk. The study included 5 family health centers in each district. In this context, 15 nurses were interviewed. 16 questions about the subject were prepared by using literatüre and expert opinions. An average of 15 minutes was interviewed with each nurse. As a result of theinterviews conducted in theresearch, there are 4 themes, including the reasons for anti-vaccination, the reasons for vaccination, the ways to obtain information about vaccines, the methods of protecting the children of non-immunized families and the solutions of health workers. The reasons for families against vaccination consist of 7 sub-categories, 3 sub-categories of informationacquisition, 5 sub-categories of protection of children of families, and 4 subcategories of solutions of health workers. Families have shown reasons such as the presence of mercury, paraben, the effect of religious groups and the import of vaccines from abroad. It has been seen that families get information about vaccines especially from internet and social media groups. Families who do not have
\end{abstract}

\footnotetext{
* Doç. Dr. Selçuk Üniversitesi, Sağlık Bilimleri Fakültesi, Sağlık Yönetimi Bölümü

Assoc. Prof. Dr. Selcuk University, Faculty of Health Sciences, Department of Health Management

ORCID 0000-0003-1794-0296

handanertas42@gmail.com

** Arş. Gör. Dr Kahramanmaraş Sütçü İmam Üniversitesi, İktisadi ve İdari Bilimler Fakültesi, Sağlık Yönetimi Bölümü

Res. Asst. Kahramanmaras Sutcu Imam University, Faculty of Economics and Administrative Sciences, Department of

Health Management

ORCID 0000-0002-8032-1116

ramazan46k@gmail.com

*** Sağlık Bilimleri Fakültesi, Sağlık Yönetimi Bölümü

Selcuk University, Faculty of Health Sciences, Department of Health Management

ORCID 0000-0002-0526-1651

snurunal1@gmail.com

Cite as/ Atıf: Ertaş, H., Kıraç, R., Ünal, S. N. (2020). Ailelerin aşı karşıtlığı tutumlarının hemşireler tarafından değerlendirilmesine yönelik nitel bir çalışma, Turkish Studies - Social, 15(3), 1149-1163. https://dx.doi.org/10.29228/TurkishStudies.41993

Received/Geliş: 03 March/Mart 2020

Accepted/Kabul: 25 April/Nisan 2020

Copyright $(C$ INTAC LTD, Turkey

Checked by plagiarism software

Published/Yayın: 30 April/Nisan 2020

CC BY-NC 4.0
} 
vaccines think that they can protect their children with trust and alternative medicinea pplications. On the other hand, the interviewed nurses stated that public spots, domestic vaccine production and state sanctions would be effective for the solution of this issue.

Structured Abstract: In this study, it was aimed by nurses to evaluate the reasons why parents are antivaccine, from which sources they are affected, how they protect their children without vaccination, in short, the attitudes of patients against vaccination. Qualitative research method and case science pattern wereused in thisstudy. A semi-structured interview form was created using the literatüre and expert opinions on the subject as a data collection tool in there search. Face-to-face interview technique was used in the study. The research was analyzed by the maticanalysis method. In thestudy, the participants were first asked for permission to make a voice recording according to ethical rules, and the voice recordings of the participants were taken and the nanalyzed and converted into text. The texts were given to the participants and the records were confirmed to be accurate and accurate. Thus, the reliability of the research is ensured. Code names were used instead of participant names due to ethical rules. The scope of this study is limited to qualitative interviews with nurses in order to understand the attitudes of the families applying to the selected Family Health Center in Konya. The average values of the numerical data requested from the nurses during the interview and making comments on the basis of the region using these data are among the limitations of the study. The study was conducted in three districts located in Konya. The study included 5 family health centers located in each county. In this context, 15 nurses were interviewed. 16 questions prepared by using literatüre and expert opinions on the subject were addressed. An average of 15 minutes with each nurse. we've been interviewed. Nurses involved in the study were asked to comment on the families ' financial status and educational status. Accordingly, it was concluded that $53.3 \%$ of families who did not want to be vaccinated had a secondary education level and were generally high school graduates, $26.6 \%$ had a primary schooland $20 \%$ had a university degree. In the study, nurses were asked about there asonscited by families who did not want to be vaccinated. The nurses who participated in the study found that families who did not want to receive the vaccine were suspicious about the content of the vaccines $(93.3 \%)$, that religious groups were effective $(66.6 \%)$, and that some diseases such as autism linked the increase to the vaccine (40\%). Apart from that, some families that are in the minority as justification vaccines, serious side effects such as infertility $(13.3 \%)$ and the implementation of vaccines (13.3\%) surveyed nurses of thefamilyarefoundto be effective anti-vaccinerhetoric, especially in thepower of the internet andsocialmediagroups (\%86.6) outside of religious groups $(\% 46.6)$ of health personnel and some anti-vacciner hetoric $(33.3 \%)$ concluded that they have been affected. In addition, when we asked the parents about their views on whether social media was effective in anti-vaccination, all of the nurses interviewed (100\%) agreed. Social media and the internet play a decisive role in determining families ' anti-vaccine attitudes. The nurses who participated in the study were asked the question of how they thought families who did not get vaccinated would protect their children. The nurses involved in the study believe that anti-vaccine families are able to protect their children with trust (40\%), natural nutrition and Natural Living (20\%), alternative medicine practices (20\%). 53.3\% of the nurses who participated in the study argued that there should be a state sanction for vaccines and that it could only be solved in this way, while $20 \%$ of the nurses argued that switching to domestic vaccine production would contribute to the solution of the problem. Furthermore, $40 \%$ of the participants argued that public spot light could be effective in solving this issue. There are various social, cultural and psychological factors that will determine the families ' attitude to vaccines. One of these factors is the educational status of families. Adisa et al. (2016), Kassahun et al. (2015), Gust et al. (2005), Owais et al. (2011) study concluded that vaccination rates will increase as parents ' level of education increases. This study concluded that the majority of families who are anti-vaccine are high school graduates. However, only $20 \%$ of the nurses expressed that their families wer euniversity graduates. $93.3 \%$ of the nurses interviewed stated that they did not trust the content of the vaccines as the most obvious reason for their families ' anti-vaccine attitudes. $40 \%$ of families are particularly suspicious about mercury, which is one of the ingredients of the vaccine, and argue that mercury can cause autism. In parallel with these results found, Benin et al. (2006), Allan et al. (2015), studies also concluded that autism was effective in families ' anti-vaccine attitudes. Only $13.3 \%$ of nurses said families were worried about side effects. Similarly, Montenegro et al. (2015), studies have found that side effects are effective in people's attitudes to wards the vaccine. Burgshouts et al. in their study in 2017, suggesting that families who did not get vaccinated had side effects of vaccines as the most obvious justification. $60 \%$ of the nurses involved in the study expressed that their families were affected by some religious groups. In parallel with this result, Taylor et al. (2017), Wenger et al. (2011) studies concluded that religious beliefs and groups are effective in vaccination attitudes. It was concluded that they were influenced by their rhetoric (33.3\%) .In addition, when we asked the parents about their views on whether social media waseffective in anti-

Turkish Studies - Social, 15(3) 
vaccination, all of thenurses interviewed (100\%) agreed. Social media and the internet play a decisive role in determining families ' anti-vaccine attitudes. The nurses who participated in the study were asked the question of how they thought families who did not get vaccinated would protect their children. The nurses involved in the study believe that anti-vaccine families are able to protect their children with trust (40\%), natural nutrition and Natural Living (20\%), alternative medicine practices $(20 \%) .53 .3 \%$ of the nurses who participated in the study argued that there should be a state sanction for vaccines and that it could only be solved in this way, while $20 \%$ of the nurses argued that switching to domestic vaccine production would contribute to the solution of the problem. Furthermore, $40 \%$ of the participants argued that public spot light could be effective in solving this issue. $33 \%$ of the nurses participating in the study stated that thevaccines originating from abroad are effective in the anti-vaccination attitude of the families. Apart from this, $13.3 \%$ of the nurses state that families display an anti-vaccination attitude due to the way they are administered. Administration of oral vaccines such as opa vaccine may increase vaccination rates. It is observed that families' past vaccination experiences are also effective in this regard. It was concluded that $86 \%$ of the nurses interviewed were affected by the internet and various social media groups, $46.6 \%$ of them were religious group sand $33.3 \%$ of them were the influences of health workers. Families who are anti-vaccination try to obtain information by contacting the internet and various socialmedia groups since sufficient information about vaccines is not provided. In their study, Bodemer et al. (2012), Wiley et al. (2017) concluded that not all media sources make balanced reporting. It is learned from nurses that families get information especially from groups on Facebook and that they learn natural ways of protection from various diseases. Doctors and healthcare providers are emphasized in numerous studies as the most common and reliable source of information about vaccination. Especially the anti-vaccination discourses of people who are competent in the field of health and some physician schange the attitudes of the public to wards the vaccine significantly. Therefore, attitudes of healthcare professionals are one of the most important factors in preventing anti-vaccination. The nurses stated that most anti-vaccine parents are fatalistic, believe that they need to rely on diseases, that natural living and natural nutrition will eliminate diseases and that alternative medicine practices will better protect them from diseases. Bryden et al.(2017) studies have been identified as a possible factor in developing vaccine skepticism and vaccine rejection of alternative medicine practices. It is important to take effective measures to change the negative outlook on the vaccine, which is the most reliable and cheapest method that can be taken to protect the health of the individual and the community. In studies on child vaccination, one of the most reported reasons for low vaccination rates has been that parents find the information provided inadequate. Families should be adequately informed about this issue by experts, positive information and publications should be made from the internet, television and newspapers (publicspotlight), and parents should be trusted with vaccinations thanks to well-trained medical staff. Andres et al. In a 2009 study in the city of Madrid, vaccination rates were higher for those who believed they were adequately informed by medical staff.

Keywords: Vaccine, Anti Vaccine, Vaccine Rejection, Qualitative Research

Öz: Bu çalışmada ailelerin aşı karşıtı olmalarının nedenleri, hangi kaynaklardan etkilendikleri, çocuklarını aşısız nasıl korudukları kısacası ailelerin aşı karşıtı tutumlarının hemşireler tarafından değerlendirilmesi amaçlanmıştır. Bu çalışmada nitel araştırma yöntemi ve olgu bilim deseni kullanılmıştır. Araştırmada veri toplama aracı olarak konu ile ilgili literatürden ve uzman görüşlerinden yararlanılarak oluşturulan yarı yapılandırılmış bir görüşme formu oluşturulmuştur. Çalışmada yüz yüze görüşme tekniği kullanılmıştır. Araştırma tematik analiz yöntemi ile analiz edilmiştir. Çalışma Konya'da bulunan üç ilçede yapılmıştır. Bu ilçeler Karatay, Meram ve Selçuklu 'dur. Çalışmaya, her ilçede bulunan 5 aile sağlığı merkezi dâhil edilmiştir. Bu bağlamda 15 tane hemşire ile görüşülmüştür. Konu ile ilgili literatür ve uzman görüşlerinden yararlanılarak hazırlanan 16 soru yöneltilmiştir. Her bir hemşire ile ortalama $15 \mathrm{dk}$. Görüşme yapılmıştır. Araştırmada yapılan görüşmeler sonucunda aşı karşıtlığı ile ilgili ailelerin aşı karşıtlığı gerekçeleri, aşılarla ilgili bilgi edinme yolları, aşı yaptırmayan ailelerin çocuklarını koruma yöntemleri ve sağlık çalışanlarının çözüm önerileri olmak üzere 4 tane tema bulunmaktadır. Ailelerin aşı karşıtlığı gerekçeleri 7 alt kategoriden, bilgi edinme yolları 3 alt kategoriden, ailelerin çocuklarını koruma yöntemleri 5 alt kategoriden ve sağlık çalışanlarının çözüm önerileri ise 4 alt kategoriden oluşmaktadır. Aileler aşı karşıtı tutumlarına gerekçe olarak içeriğinde cıva, paraben gibi maddelerin bulunması, dini grupların etkisi, aşıların yurt dişından ithal edilmesi gibisebepler göstermiştir. Ailelerin aşılarla ilgili özellikle internet ve sosyal medya gruplarından bilgi edindikleri görülmüştür. Aşı yaptırmayan aileler çocuklarını tevekkül ile alternatif tıp uygulamaları gibi

www.turkishstudies.net/social 
uygulamalarla koruyabileceklerini düşünmektedirler. Buna karşılık görüşülen hemşireler bu konunun çözümü için kamu spotlarının, yerli aşı üretiminin ve devlet yaptırımlarının etkili olacağını söylemişlerdir.

Anahtar Kelimeler: Aşı, Aşı karşıtlığı, Aşı reddi, Nitel araştırma

\section{Giriş}

İnsanlık tarihi boyunca çeşitli salgın hastalıklar görülmüş ve bu salgınlarda milyonlarca insan hayatını kaybetmiştir. Geçmişten günümüze birçok pandemi ortaya çıkmış ve bu tür hastalıkların tedavisi ile ilgili araştırmalar yapılmıştır (Kutlu ve Altındiş, 2018:47). Bu hastalıklara karşı alınabilecek en etkili önlemin aşılama olduğu ise yadsınamaz bir gerçektir (Bozkurt, 2018:71). Aş1, yapay bir bağışıklık kazanmak için hastalıkların oluşumunda etkili olan virüs veya bakterilerin hastalık yapma karakterinden arındırılarak vücuda enjekte edilmesi sonucu vücudun onu tanıması ve savunma sistemi geliştirmesini sağlayan koruyucu bir yöntemdir (Altun, 2008:132; Seval, Acar, 2018:159). Etkili bir bağışıklama, çocukluk dönemlerinde aşı ile önlenebilen hastalıklardan korunmayı hatta ileri yaşlarda da bu hastalıkların en az zararla atlatılmasını sağlayan değerli bir hizmettir (Kürtüncü, 2017). Geçmişten günümüze enfeksiyonlu hastalıkların tedavisinde, salgın hastalıkların ortadan kaldırılmasında, hastalığın kişiler arası yayılımının engellenmesinde etkin rol alan aşı, çeşitli önlemlerle kitle bağışıklığına da katkı sağlamaktadır. 2000 yılındaki Milenyum Zirvesin'de Binyıl Kalkınma Eylemleri kapsamında da aşılamanın önemi vurgulanmıştır (Fagundes vd., 2017:9).

1974 y1lında aşıların çiçek hastalığının eradike edilmesi üzerindeki başarısı üzerine Dünya Sağlık Örgütü (DSÖ) tarafından hayat kurtarıcı bu aşıların tüm ülkelerde uygulanması için "Aşılar İçin Genişletilmiş Program" başlatılmıştır ve bu programdan sonra aşılarla ilgili tüm ülkeler de geniş kapsamlı kampanyalar yapılmaya başlanmıştır. Ülkemizde 1960 yılında 5 hastalığa karşı aşılama yapılırken uygulanan kampanyalar sayesinde 2012 yılı itibariyle bu sayı 13'e çıkarılmıştır (Sağlık Bakanlığı, 2019:80). Şu an aşı takvimimizde bir değişiklik olmayıp halen 13 hastalığa karşı aşılama uygulanmaktadır. DSÖ'nün 2018 verilerine göre her yıl yaklaşık 1,5 milyon insan, aşı ile önlenebilecek hastalıklardan dolayı yaşamını kaybetmektedir (who.int). Aşılama uygulamaları sayesinde 2002 yılından beri polio vakası görülmemektedir (Gülcü ve Arslan, 2018:35). Bu nedenle DSÖ tarafından 21 Haziran 2002'de Türkiye'ye Poliodan Arındırılmış Bölge Sertifikası verilmiştir (Ataç vd., 2014:43). 2018 verilerine göre ise 5 yaş altı çocuklarda 2015 yılı itibariyle aşılanma sonrası Hepatit B görülme sıklı̆̆1 \%5’ten \%1'e düşmüştür (WHO, 2018:6). Ayrıca Sağlık Bakanlığ 2018 verilerine göre 2002 yılında \%75'lerde olan aşılama oranları 2016 itibari ile \%95'in üzerinde olduğu görülmüştür (Sağlık Bakanlığı, 2016:67). DSÖ 2018 verilerine göre küresel aşı kapsamı halen \%85'tir (who.int).

Bütün bu gelişmelere rağmen belli gruplar aşıya şüpheyle yaklaşmışlar; yararlarını tartışmaktan daha çok ciddi zararlarının olabileceğini savunarak, nedeni bilinmeyen patolojilere karş1 aşıları hedef göstermiş ve aşı uygulamalarına karşı çıkmışlardır (Badur,2011:82). Sosyal medya ve internetinde etkisiyle bu grupların aşı karşıtı söylemleri, aşılama oranlarını ciddi manada etkilemiş̧tir. Bunun sonucu olarak ortaya aşı karşıtlığı kavramı çıkmıştır. Aslında kavram 1800'lü yıllarda İngiltere'de çiçek salgınında halka yeterli bilgi verilmeden yapılan zorunlu aşı uygulamalarında aşı yaptırmak istemeyenlere ağır cezalar verilmesi sonucu doğmuştur ve bu uygulama halk tarafından tepki ile karşılanmıştır (Boom vd., 2014:4). Avrupa ve Amerika'da uzun yıllardır baş gösteren bu sorun, son 8 yıldır ülkemizde de etkili olmaya başlamıştır. Sağlık Bakanlığı verilerine göre 2016 yılında her bir antijen için aşılama hızımız \%98'lerde iken 2017 yılında bu oranlar \%96' ya gerilemiştir (Sağlık Bakanlığı, 2019:77). 2016 yılında \%96 olan verem aşısı uygulama hızı ise 2017 yılı itibari ile \%93 e düşmüştür (Sağlık Bakanlığı, 2019:77). Bu veriler konuyla ilgili gerekli bilgilendirme ve yaptırımların yapılmasını gerektiğini ortaya koymaktadır. Yapılan çalışmalarda aşıların içeriğindeki cıva, alüminyum gibi kimyasal maddeler suçlanmış,

Turkish Studies - Social, 15(3) 
aşıların otizme yol açabileceği, ciddi yan etkilerinin olabileceği düşünülerek aşılar suçlanmıştır (Brandt vd., 2011; Çapanoğlu, 2018; Jacobson vd., 1997; Mckeever vd., 2004; Karadağ vd., 2015; Örmen vd., 2009; Taylor vd., 2002; Kondo vd., 2012; Burghouts vd., 2017). Bunların dışında dini inançlar ve bazı dini liderlerin etkileri, sağlı personellerinin aşı karşıtı tutumları ve uygulama öncesi yeterli bilgilendirme yapılmaması, aşılara olan güvensizlik, aşı üreten firmalara olan güvensizlik, aşının etkinliğinden şüphe duyma, aşıların uygulanış şekilleri, doğal yöntemlerin aşıdan daha etkili olabileceği düşüncesi gibi çeşitli nedenler ileri sürülerek aşı karşıtlığı haklı gösterilmeye çalışılmıştır (Taylor vd., 2017; Reading vd., 2004;Wenger vd., 2011; Gust vd., 2005; Smailbegoviç vd., 2003; Sevencan vd., 2009; Yaqub vd., 2014; Hausman vd., 2014). Yapılan çalışmalarda sosyal medya ve internetin aşı karşıtlığının artmasındaki rolü vurgulanmıştır (Attwell vd.,2018; Davies vd., 2002). Ayrıca çalışmalarda ebeveynlerin eğitim düzeyi, gelir durumu, çocuk sayısı gibi etkenlerin ailelerin aşılara karşı tutumları üzerindeki etkisi incelenmiştir (Hornsey vd., 2018; Yiğitalp vd., 2008).

$\mathrm{Bu}$ çalışmada hemşireler tarafından ebeveynlerin aşı karşıtı olmalarının nedenleri, hangi kaynaklardan etkilendikleri, çocuklarını aşısız nasıl korudukları, kısacası hastaların aşı karşıtlığı tutumlarının değerlendirilmesi amaçlanmıştır.

\section{Gereç ve Yöntem}

$\mathrm{Bu}$ çalışmada nitel araştırma yöntemi ve olgu bilim deseni kullanılmıştır. Çalışma Ocak 2018- Nisan 2018 tarihleri arasında gerçeklemiştir. Araştırmada veri toplama aracı olarak konu ile ilgili literatürden ve uzman görüşlerinden yararlanılarak oluşturulan yarı yapılandırılmış bir görüşme formu oluşturulmuştur. Çalışmada yüz yüze görüşme tekniği kullanılmıştır. Araştırma tematik analiz yöntemi ile analiz edilmiştir. Araştırmada önce etik kurallar gereği ses kaydı yapmak için katılımcılardan izin istenmiş ve izin veren katılımcıların ses kayıtları alınmış ve daha sonra çözümlenip metne dönüştürülmüştür. Metinler katılımcılara verilerek kayıtların yanlışsız ve doğru olduğu teyit ettirilmiş. Böylece araştırmanın güvenilirliği sağlanmıştır. Veri analizinin güvenirliliğinin ve inandırıcılığının artırılması için katılımcıların ifadeleri iki araştırmacı tarafından bağımsız olarak kodlanmıştır. Her bir veri analizi yapan araştırmacı bağımsız olarak kod listesi, tema ve alt soruları oluşmüş; sonrasında analizler karşılaşmış, farklılıklar tartışılmış ve ortak kodlar belirlenmiştir. Araştırmada yapılan görüşmeler sonucunda aşı karşıtlığı ile ilgili ailelerin aşı karşıtlığı gerekçeleri, aşılarla ilgili bilgi edinme yolları, aşı yaptırmayan ailelerin çocuklarını koruma yöntemleri ve sağlık çalışanlarının çözüm önerileri olmak üzere 4 tane tema bulunmaktadır. Ailelerin aşı karşıtllı̆g gerekçeleri 7 alt kategoriden, bilgi edinme yolları 3 alt kategoriden, ailelerin çocuklarını koruma yöntemleri 5 alt kategoriden ve sağlık çalışanlarının çözüm önerileri ise 4 alt kategoriden oluşmaktadır. Etik kurallar gereği katılımcı isimleri yerine kod adlar kullanılmıştır. Bu çalışmanın kapsamı Konya ilinde seçilen Aile Sağlı̆̆ 1 Merkezine başvuran ailelerin aşı karşıtlığ konusundaki tutumlarını anlamak için hemşirelerle ile yapılan niteliksel görüşmeler ile sınırlıdır. Görüşme sırasında hemşirelerden istenen sayısal verilerin ortalama değerler olması ve bu verilerden faydalanarak bölge bazında yorumların yapılması çalışmanın sınırlılıklarındandır. Çalışma Konya'da bulunan üç ilçede gerçekleşmiştir. Bu ilçeler Meram, Selçuklu ve Karatay'dır. Bu ilçelerin seçiminde Konya'nın merkez ilçeleri olması, bu bölgelerin farklı demografik özelliklere sahip bireyleri barındırması ve ulaşım kolaylığının sağlanması amaçlanmıştır. Çalışmaya, her ilçede bulunan 5 aile sağlığı merkezi dâhil edilmiştir. Bu bağlamda 15 tane hemşire ile görüşülmüştür. Nitel araştırmalarda çalışmacılar küçük bir örneklem grubunun konuyla ilgili deneyimlerini görüşme veya gözlem yöntemleri ile tespit etmeye çalışırlar (Başkale, 2016:26). Nitel araştırma yöntemleri ve olgu bilim deseni ile yapılan çalışmalarda örneklem seçiminde küçük gruplar tercih edilmektedir. İslamoğlu ve Alnıaçı (2014) nitel araştırmalarda nicel araştırmalarda olduğu örneklemin nicel olarak evreni temsil gücüne bakılmayacağını ve önemli olanın örneklem seçiminin orijinalliği olduğunu vurgulamıştır. Yıldırım ve Şimşek (2016) bu orijinalliğin sağlanabilmesi için olasılık temelli örneklem yöntemlerinden ziyade kontrollü ve amaçlı örnekleme yöntemlerinin kullanılması gerektiğinin altını çizmiştir. Bu 
bağlamda bu çalışmada hedeflenen amaçlara ulaşabilmek için ve konuyla ilişkili oluşturulan sorulara hâkim olduğuna inanılan kişilere ve sağlıklı verilere ulaşabilmek maksadıyla amaca yönelik örneklem seçilmiştir. Konu ile ilgili literatür ve uzman görüşlerinden yararlanılarak hazırlanan 16 soru yöneltilmiştir. Her bir hemşire ile ortalama $15 \mathrm{dk}$. Görüşme yapılmıştır. Yapılan görüşmelerde görüşme tekniklerinden yarı yapılandırılmış görüşme tekniği kullanılmıştır. Böylece yapılan görüşmenin akış durumuna göre gerekli alt ya da yan sorular sorularak konunun detaylandırılması amaçlanmıştır. Çalışmaya sadece Aile Sağlığı Merkez'lerinde görev yapan hemşireler dâhil edilmiştir. Aile Sağlığı Merkez'lerinde görüşülen hemşire sayısı ve görüşme süresi tabloda verilmiştir.

Tablo 1: ASM' ler de görüşülen hemşire sayısı ve görüşme süreleri

\begin{tabular}{|c|c|c|}
\hline $\begin{array}{c}\text { Katılımc1 } \\
\text { No }\end{array}$ & Katılımcı Adı & Görüşme Süresi \\
\hline 1 & Dilek Hemşire & $32 \mathrm{dk}$. \\
\hline 2 & Selma Hemşire & $30 \mathrm{dk}$. \\
\hline 3 & Merve Hemşire & $14 \mathrm{dk}$. \\
\hline 4 & Fatma Hemşire & $25 \mathrm{dk}$. \\
\hline 5 & Ayşe Hemşire & $12 \mathrm{dk}$. \\
\hline 6 & Sena Hemşire & $11 \mathrm{dk}$. \\
\hline 7 & Ferda Hemşire & $15 \mathrm{dk}$. \\
\hline 8 & Özlem Hemşire & $12 \mathrm{dk}$. \\
\hline 9 & Ayla Hemşire & $18 \mathrm{dk}$. \\
\hline 10 & Zehra Hemşire & $14 \mathrm{dk}$. \\
\hline 11 & Gülşen Hemşire & $10 \mathrm{dk}$. \\
\hline 12 & Sema Hemşire & $9 \mathrm{dk}$. \\
\hline 13 & Büşra Hemşire & $14 \mathrm{dk}$. \\
\hline 14 & Handan Hemşire & $12 \mathrm{dk}$. \\
\hline 15 & Seda Hemşire & $9 \mathrm{dk}$. \\
\hline
\end{tabular}

\section{Bulgular}

Çalışmaya katılan hemşirelerin verdikleri cevaplar aşağıda analiz edilmiştir. Araştırmada seçilen üç bölgenin her birinde 5 Aile Sağlığı Merkezi ile görülmüş olup toplamda 15 Aile Sağlığı Merkezi ile görüşme yapılmıştır. Bu bağlamda görüşülen ilçelerde toplam aşı olması gereken bebek sayıs1 3260, aş1 reddi sayıs1 191 iken ortalama aş1 reddi oran1 \%5,85'tir. Bu soru hemşirelere sorulurken ortalama değerler istenmiştir. $\mathrm{Bu}$ verilen değerlerin ortalama değerler oldukları unutulmamalıdır. Yarı yapılandırılmış soru formunda bulunan sorular ve ele alınan temalar aşağıda detaylandırılmıştır. Temaya ilişkin katılımcı görüşlerinde görüşülen hemşirelerin hepsinin görüşlerine yer verilmemiştir. Görüşme sonucunda oluşturulan tema ve kategoriler çerçevesinde ortak olan ve detaylı cevaplanmış olan birkaç hemşirenin görüşlerine yer verilmiştir. 
Tablo 2: Görüşme sonucun oluşan kategoriler ve temalar

\begin{tabular}{|c|c|}
\hline Kategoriler & Temalar \\
\hline Ailelerin aşı reddi gerekçeleri & $\begin{array}{ll}\text { - } & \text { Aşıların İçerikleri } \\
\text { - } & \text { Aşıların Yan Etkileri } \\
\text { - } & \text { Aşıların Uygulanma Şekli } \\
\text { - } & \text { Dini İnanç ve Grupların Etkisi } \\
& \text { Aşların Yurt Dışı Menşeili } \\
\text { - } & \text { Geçmiş Aşı Tecrübeleri } \\
\text { - } & \text { Bazı Hastalıkların Artışının } \\
& \text { Aşılara Bağlanması (Otizm) }\end{array}$ \\
\hline $\begin{array}{c}\text { Ailelerin Aşılarla İlgili Bilgi Edinme } \\
\text { Yolları }\end{array}$ & $\begin{array}{ll}\text { - } & \text { Dini Grupların Etkisi } \\
\text { - } & \text { Internet ve Çeşitli Sosyal Medya } \\
& \text { Grupları } \\
\text { - } & \text { Sağlık Çalışanlarının Söylemleri }\end{array}$ \\
\hline $\begin{array}{c}\text { Aş1 yaptırmayan Ailelerin Çocuklarını } \\
\text { Koruma Yöntemleri }\end{array}$ & $\begin{array}{ll}\text { - } & \text { Tevekkül Etmek } \\
\text { - } & \text { Doğal Yaşama ve Doğal } \\
& \text { Beslenme } \\
\text { - } & \text { Kalabalık Ortamlardan Uzak } \\
& \text { Tutmak } \\
\text { - } & \text { Alternatif Tıp Uygulamaları } \\
\text { - } & \text { Aşı yaptırmayarak } \\
\end{array}$ \\
\hline $\begin{array}{c}\text { Sağlık Çalışanlarının Çözüm } \\
\text { Önerileri }\end{array}$ & $\begin{array}{l}\text { - } \begin{array}{l}\text { Devlet yasa ile güvence altına } \\
\text { almalı }\end{array} \\
\text { - } \text { Kamu spotları } \\
\text { - } \quad \text { Yerli Aşı üretimi } \\
\text { - Halkın Bilgilendirilmesi }\end{array}$ \\
\hline
\end{tabular}

\section{Aşı karşıtı ailelerin eğitim durumları ile ilgili neler söyleyebilirsiniz?}

Çalışmaya katılan hemşirelere ailelerin maddi durum ve eğitim durumları hakkında yorum yapması istenmiştir. Buna göre hemşirelerin \%53,3' ü aş1 yaptırmak istemeyen ailelerin orta derecede eğitim düzeyine sahip olduğu ve genelde lise mezunu olduğu, \%26,6's1 ilkokul ve \%20'si Üniversite mezunu olduğu sonucuna ulaşılmıştır.

\section{Temaya İlişkin Katılımcı Görüsşleri}

"Maddi durumu, eğitim düzeyi düşük olan aileler zaten ne desek yaplyorlar. Ama bu dediğimiz kesim yani kendini bilinçli zannedip bilinçli olmayanlarla ilgili; orta seviyede eğitim düzeyine sahip kişiler denebilir(Gülşen hemşire)."

"Bu aileler için orta seviyede eğitim düzeyine sahip lise mezunu denebilir. Genellikle ev hanımı oldukları söylenebilir. Arada yüksek eğitim düzeyine sahip insanlar da çıkabiliyor onları ikna etmek oldukça zor çünkü zaten bizden çok bildiklerini düşünüyorlar (Selma hemşire)."

"Genelde kültürlü, eğitim düzeyi yüksek olan aileler. Sadece aşı yaptırmayan 5 kişiden 3 tanesi ögretmendir (Dilek hemşire).” 


\section{Aşı yaptırmak istemeyen aileler gerekçe olarak ne gösteriyorlar?}

Çalışmada hemşirelere aşı yaptırmak istemeyen ailelerin gerekçe olarak gösterdiği sebepler sorulmuştur. Verilen cevaplar aşağıda tablolar halinde sıralanmıştır.

Tablo 3: Aşı Karşıtı Ailelerin Gerekçeleri

\begin{tabular}{lcc}
\hline \multicolumn{1}{c}{ Temalar } & f & \% \\
\hline Aşıların İçerikleri (paraben, civa, alimünyum, domuz geni) & 14 & 93.3 \\
\hline Dini Grup/ İnanışların Etkisi & 10 & 66.6 \\
\hline Bazı Hastalıkların Artışının Aşılara Bağlanması (Otizm) & 6 & 40 \\
\hline Aşıların Yurt Dışından İthal Edilmesi & 5 & 33.3 \\
\hline Aşıların Yan Etkileri & 2 & 13.3 \\
\hline Aşıların Uygulanma Şekli & 2 & 13.3 \\
\hline Geçmiş Aşı Tecrübeleri & 2 & 13.3 \\
\hline
\end{tabular}

Araştırmaya katılan hemşireler, aşı yaptırmak istemeyen ailelerin gerekçe olarak aşıların içerikleri konusunda şüpheli oldukları $(\% 93,3)$, dini grupların etkili olduğunu $(\% 66,6)$, otizm gibi bazı hastalıkların artışını aşıya bağladıklarını (\%40) gibi sebepler ileri sürdükleri görülmüştür. Bunun dışında azınlıkta olan bazı aileler ise gerekçe olarak aşıların kısırlık gibi yan etkileri $(\% 13,3)$ ve aşıların uygulanış şekillerinin $(\% 13,3)$ etkili olduğu görülmüş̧ür.

\section{Temaya İlişkin Katılımcı Görüşleri}

"Aşı yaptırmak istemeyen aileler gerekçe olarak aşıların cıva, domuz geni içerdiğini, yurtdışından ithal edildiğini gibi sebepler ileri sürüyorlar. Bazı ailelerde özellikle otizm şüphesi var. Aileler bu konuda özellikle cıvayı suçlamaktadırlar" (Dilek hemşire).

"Bazen 34 aşıyı aynı anda yapıyoruz bu sıkıntı olabiliyor. Belki ayrı zamanlarda yapılsa daha iyi olur. Aynı anda bebeğe çok fazla intramüsküler uygulandiğını düşünüyorlar. Hatta bir hastamın aşı reddi sebebi buydu. Son aldiğımız ĕ̆itimde 5 yıla kadar opa gibi oral aşılara geçileceğini söylediler. Belki bu şekilde biraz olsun karşıtlık düşebilir. Çocuğun canı çok yanıyor diye yaptırmayanlar yaptırabilir" (Ayla hemşire).

"Aşıların yurt dışından gelmesi, içeriğinde ne olduğunun bilinmemesi, bir de geçmiş̧ aşı tecrübeleri de önemli. Özellikle bazı aşıların yan etki olarak ateş yapması aileleri korkutuyor. Bir kere yaptırdık çok ateşi çıktı artık yaptırmayacağız diyenler olabiliyor. Özellikle aşıların yurt dışında gelmesi sıkıntı mesela aşı redlerimden bir tanesi aşılarını Danimarka da yaptırıyor" (Sena hemşire).

\section{Aşı yaptırmayan aileler aşılarla ilgili hangi kaynaklardan etkileniyorlar?}

Araştırmaya katılan hemşirelere ailelerin hangi kaynaklardan etkilendiklerine dair görüşleri sorulmuştur. Alınan cevaplar başlıklar halinde sıralanmıştır.

Tablo 4: Ailelerin Aşılarla İlgili Bilgi Edinme Yolları

\begin{tabular}{ccc}
\hline Temalar & f & \% \\
\hline İnternet ve Çeşitli Sosyal Medya Grupları & 13 & 86.6 \\
\hline Dini Grupların Etkisi & 7 & 46.6 \\
\hline Sağlık Çalışanlarının Söylemleri & 5 & 33.3 \\
\hline
\end{tabular}

Araştırmaya katılan hemşireler ailelerin aşı karşıtı söylemlerinde özellikle internet ve sosyal medya gruplarının etkili olduğunu (\%86.6) bunun dişında dini grupların (\%46.6) ve bazı sağlık personellerinin aşı karşıtı söylemlerinden (\%33.3) etkilendikleri sonucuna ulaşılmıştır. 
Ayrıca bir diğer soruda ailelerin aşı karşıtı olmalarında sosyal medyanın etkili olup olmadı̆̆ hakkındaki görüşlerini sorduğumuzda görüşülen hemşirelerin hepsinin (\%100) bu konuda hemfikir olduğu görülmüş̧ür. Ailelerin aşı karşıtı tutumlarının belirlenmesinde sosyal medya ve internetin belirleyici rol oynadı̆̆ görülmektedir.

\section{Temaya İliş̧kin Katılımcı Görüşleri}

"Özellikle aileler internetten ve çeşitli dini gruplardan etkileniyorlar. Bir grup var biz burada onlara İnternet âlimi diyoruz internetten okudukları sebebi ile aşı yaptırmıyorlar. Bir grup var dini grupların etkisinden dolayı yaptırmıyorlar. Özellikle Facebook ta açılan bazı gruplardan halkımız çok etkileniyor. "Günümüzün kitle imha silahı: aşılar", "AYMD” gibi gruplar mevcut. Buralarda yapılan bazı paylaşımlar gerçekten insanı şüpheye düşürecek kadar etkili olduğunu düşünüyorum. Sağllk personelleri özellikle bu konuda sağllk alanında çalışan personele daha fazla sorumluluk düşmektedir. Halkımız özellikle hekimlerin, hemşirelerin, diğer sağlık personellerinin tutumundan oldukça etkilenmektedirler. Bazı hekimlerin aşı karşıtı söylemleri halkın aşıya olan tutumlarını ciddi manada etkilemektedir ve değişstirmektedir" (Selma hemşire)

"Internet ve dini gruplardan çok etkileniyorlar. Bir hastam normalde hep aşılarını yaptırırdl. Sonradan yaptırmamaya başladı. Sebebini sorduğumda ise girdiği dini grubun uygun bulmadı̆̆ını söyledi. (Zehra hemşire)

\section{Aşı karşıtı aileler çocuklarını ne şekilde koruduklarına inanıyorlar?}

Çalışmaya katılan hemşirelerden aşı karşıtı ailelerin çocuklarını ne şekilde koruduklarına inandıklarına dair görüşleri sorulmuş ve verilen cevaplar tabloda başlıklar halinde sıralanmıştır.

Tablo 5: Sağlık Personellerinin Çözüm Önerileri

\begin{tabular}{|c|c|c|}
\hline Temalar & $\mathbf{f}$ & $\%$ \\
\hline Tevekkül Etmek & 6 & 40 \\
\hline Doğal Yaşama ve Doğal Beslenme & 3 & 20 \\
\hline Kalabalık Ortamlardan Uzak Tutmak & 3 & 20 \\
\hline Alternatif Tip Uygulamaları & 3 & 20 \\
\hline Aşı yaptırmayarak & 1 & 10 \\
\hline
\end{tabular}

Araştırmaya katılan hemşireler aşı karşıtı ailelerin çocuklarını tevekkül ile (\%40), doğal beslenme ve doğal yaşama ile $(\% 20)$, alternatif tıp uygulamaları $(\% 20)$ gibi yöntemlerle koruyabildiklerini düşünmektedirler.

\section{Temaya İlişkin Katılımcı Görüşleri}

"Bu aileler kaderci olup, çocuklarının Allah tarafindan korunacağını düşünüyorlar. Özellikle bağlı oldukları dini gruplardan çok etkileniyorlar. Hatta en son bir hastamız vardı. Aşı yaptırmak istemediklerini, çocuğun vücuduna boş yere virüs vermeye gerek olmadı̆̆ını, Allahın bizi doğuştan mikropsuz yarattı̆̆ın sonradan vücuda mikrop vermenin doğru olmadığın söyledi" (Ayşe Hemşire).

"Bu aileler çocuklarının doğal besinlerle besleyerek, çocuklarını hastalıklı ve kalabalık ortamlardan uzak tutarak ve genelde alternatif tıp yöntemlerini kullanarak koruduklarin söylüyorlar. Bitkisel ilaçlar hazırlyyorlar. Antibiyotik kullanmıyorlar. Internetteki aşı karşıtı grupların tariflerini kullanıyorlar. Mesela biri turp suyu ile koruduğunu düşünüyor. Bazıları aşı yaptırmayarak korudukları düşünüyor ve aşı olmayan çocuk sağllklı çocuktur, aşılar çocukları hasta ediyor diye düşünüyorlar" (Selma hemşire). 
"Alternatif tıp uygulamalarının konvansiyonel tıptan daha güvenilir olduğunu savunuyorlar. Aşı yaptırmayarak çocuklarının daha güvende olduğunu ve çocuklarını aşı yaptırmayarak koruduklarını düşünüyorlar" (Handan hemşire)

\section{Aşı karşıtlığının önlenmesi için hangi çözüm yollarını önerirsiniz?}

Çalışmaya katılan hemşirelerden aşı karşıtlığı ile ilgili çözüm önerileri istenmiştir ve verilen cevaplar tabloda başlıklar halinde sıralanmıştır.

Tablo 6: Sağllk Personellerinin Çözüm Önerileri

\begin{tabular}{lcc}
\hline \multicolumn{1}{c}{ Temalar } & f & \% \\
\hline Devletin Yasa ile Güvence Altına alması/ Devlet Yaptırımı & 8 & 53.3 \\
\hline Kamu spotları & 6 & 40 \\
\hline Yerli Aşı Üretimi & 3 & 20 \\
\hline Sağlık Personellerinin Halkı Bilgilendirmesi & 2 & 13.3 \\
\hline
\end{tabular}

Çalışmaya katılan hemşirelerin \%53,3'ü aşılarla ilgili devlet yaptırımının olması gerektiğini ve ancak bu şekilde çözülebileceği fikrini savunurken, hemşirelerin \%20'si yerli aş1 üretimine geçilmesinin problemin çözümüne katkı sağlayacağını savunmuşlardır.

\section{Temaya İlişkin Katılımcı Görüşleri}

"Devletin yasa ile güvence altına almast gerekiyor. Bireyini, toplumunu, vatandaşını koruması gerekiyor. Aşılar yerli üretime geçilse karşıtlı̆̆ın büyük bir oranda azalacağını düşünüyorum. Eğer aşıların yüzde 98-99 yapılsın isteniyorsa böyle bir şey yapılmall. Yerli aşıya geçilmeli. TV de aşıları destekleyici kamu spotlarına yer verilmeli. Herhangi bir para cezası vs. olmalı. Aşı yaptırmama konusu ailenin elinden tamamen alınmalı çocuk istismarına girmeli bu konu. Sağllk personeli insanları aşı yaptırmaya ikna etmeye uğraşmamalı devlet bir zorunluluk getirmeli ve herkes aşısını olmall. Bu konu benim için çok önemli, en basitinden kendi hesaplarım da whatsapp' ımda aşı yaptırılmaması durumunda oluşabilecek sikıntıları paylaşıyorum bu gibi paylaşımlarımdan etkilenip yaptıran aile sayısı fazla" (Fatma Hemşire).

\section{Tartışme ve Sonuç}

Ailelerin aşılara olan tutumunu belirleyecek çeşitli sosyal, kültürel ve psikolojik etkenler vardır. Bu etkenlerden biri de ailelerin eğitim durumudur. Adisa ve ark. (2016), Kassahun ve ark. (2015), Gust ve ark. (2005), Owais ve ark. (2011) çalışmalarında ebeveynlerin eğitim düzeyi arttıkça aşılama oranlarının da artacağı sonucuna ulaşmışlardır. Kürtüncü ve ark. (2017), Hornsey ve ark. (2018) çalışmalarında ise ebeveynlerin eğitim durumlarının aşılama oranlarını etkilemediği sonucunu çıkarmışlardır. Bu araştırmada ise aşı karşıtı olan ailelerin çoğunluğunun lise mezunu oldukları sonucuna varılmıştır. Bununla beraber hemşirelerin sadece \%20'si ailelerin üniversite mezunu olduklarını dile getirmişlerdir. Çapanoğlu (2018)'nun çalışmasında ise aşı karşıtı olan ailelerin eğitim durumları ile ilgili bir genellemenin yapılamayacağı gibi bir sonuç çıkarılmıştır. Görüşülen hemşirelerin \%93,3 ü ailelerin aşı karşıtı tutumlarında en belirgin gerekçe olarak aşıların içeriğine güvenmediklerini belirtmişlerdir. \%40'1 ise ailelerin özellikle aşı içeriklerinden biri olan cıva konusunda şüpheli olduklarını ve civanın otizme sebep olabileceği görüşünü savunduklarını görmekteyiz. Bulunan bu sonuçlara paralel olarak Benin ve ark. (2006), Allan ve ark. (2015), Smailbegoviç ve ark. (2003), McMurray ve ark. (2004) çalışmalarında da ailelerin aşı karşıtı tutumlarında otizmin etkili olduğu sonucuna ulaşılmışıı. Hilton ve ark. (2007)'nın çalışmasına göre ise ailelerin aşıların otizme sebep olacağı düşüncesinin olmadığı sonucuna varılmıştır. Bununla birlikte, çalışmalar cıva ve otizm arasındaki sebep-sonuç ilişkisini saptamada sürekli başarısız olmuştur. DeStefano ve ark. (2009), McKeever ve ark. (2004),Hurley ve ark. (2010) çalışmalarında cıva ile otizm arasında bir ilişki saptanamamıştır. 2009 yılı itibariyle aşıların içeriğinden cıva çıkarılmış olmasına rağmen halkın yeterince bilgilendirilmemesi nedeniyle hala 
cıva-otizm ilişkisi aşı karşıtlığına gerekçe olarak gösterilmektedir. Hemşirelerin yalnızca \%13,3 ü ailelerin yan etkiler konusunda endişeli olduklarını belirtmişlerdir. Benzer şekilde Karadağ ve ark. (2015), Taylor ve ark. (2002) çalışmalarında yan etkilerin kişilerin aşıya karşı olan tutumlarında etkili olduğunu tespit etmişlerdir. Burgshouts ve ark. 2017 yılında yaptıkları çalışmada aşı yaptırmayan ailelerin en belirgin gerekçe olarak aşıların yan etkileri olduğunu ileri sürmektedirler. Evans ve ark. (2001) çalışmalarında ise aşı yaptırmayan ailelerin çocuklarında oluşabilecek hastalıkların yan etkileri, aşıdan kaynaklanan yan etkilerden daha kabul edilebilir olarak görülmüştür Aşıların yan etkisinden çok faydaları göz önünde bulundurulmalıdır. Çalışmaya katılan hemşirelerin \%60'ı ailelerin bazı dini grup ve liderlerden etkilendiklerini dile getirmişlerdir. Bu sonuçla paralel olarak Taylor ve ark. (2017), Reading ve ark. (2004), Wenger ve ark. (2011) çalışmalarında aşılama tutumlarında dini inanç ve grupların etkili olduğu sonucuna varılmıştır. Burgshouts ve ark. (2017) çalışmasında ise din ile aşılama tutumları arasında ilişki bulunamamıştır. Hemşirelerin verdiği bilgilere göre aşı yaptırmayan bu aileler kaderci olup çocuklarının Allah tarafından korunacağını düşünmektedirler. Çalışmaya katılan hemşirelerin \%33’ü aşıların yurt dışı menşeili olmasının ailelerin aşı karşıtı tutumlarında etkili olduğunu ifade etmişlerdir. Bunun dışında hemşirelerin \%13,3'ü ailelerin, aşıların uygulanma şekilleri sebebi ile aşı karşıtı tutum sergilediklerini belirtmektedirler. Opa aşısı gibi oral olarak yapılan aşıların uygulanması aşılama oranlarını arttırabilir. Ailelerin geçmiş aşı tecrübelerinin de bu konuda etkili olduğu görülmektedir. Görüşülen hemşirelerin \%86'sı aşı karşıtı tutumu sergileyen ailelerin bu tutumlarının internet ve çeşitli sosyal medya gruplarından, $\% 46,6$ 'sı dini gruplardan ve $\% 33,3$ 'ü ise sağlık çalışanlarının söylemlerinden etkilendikleri sonucuna ulaşılmıştır. Aşı karşıtı olan aileler aşılarla ilgili yeterli bilgi verilmediği için internet ve çeşitli sosyal medya gruplarına başvurarak bilgi edinmeye çalışmaktadırlar. Bodemer ve ark. (2012), Wiley ve ark. (2017) yaptıkları çalışmalarda medya kaynaklarının tamamının dengeli raporlama yapmadığı sonucuna varılıı̧ıtır. Davies ve ark. (2002) arama motorları üzerinde yaptıkları araştırmada ilk 10 sonuçtan \%43'ünün aşılarla ilgili olumsuz görüşler bildiren sonuçlar olduğu görülmüştür. Kang ve ark. (2017), Twitter üzerinden yaptıkları araştırmada atılan tweetlerin çoğunun aşılarla ilgili olumsuz bilgiler içerdiği görülmüştür. Hemşirelerden, ailelerin özellikle Facebook’taki gruplardan (AYMD, Günümüz Kitle İmha Silahı: Aşılar) bilgi edindikleri hatta bu gruplardan çeşitli hastalıklardan doğal korunma yolları öğrendikleri bilgisine ulaşılmaktadır. Doktorlar ve sağlık hizmeti sağlayıcıları, aşılama konusunda en yaygın ve güvenilir bilgi kaynağı olarak sayısız çalışmadavurgulanmaktadır (Ames vd., 2017; Stefanoff vd., 2010).

Özellikle sağlık alanında yetkin kişilerin ve bazı hekimlerin aşı karşıtı söylemleri halkın aşıya olan tutumlarını ciddi manada değiştirmektedir. Bu nedenle sağlık çalışanlarının tutumları aşı karşıtlığının önlenmesinde en önemli etkenlerden biridir. Hemşireler, aşı karşıtı ebeveynlerin çoğunun kaderci olduğunu, hastalıklar hakkında tevekkül etmek gerektiğine, doğal yaşama ve doğal beslenmenin hastalıkları ortadan kaldıracağına, alternatif tıp uygulamalarının hastalıklardan daha iyi koruyacağına inanmakta olduğunu belirtmişlerdir. Bryden ve ark. (2017) çalışmalarında, alternatif tıp uygulamalarının aşı şüpheciliği ve aşı reddinin geliştirilmesinde olası bir faktör olarak tanımlanmıştır.

Bireyin ve toplumun sağlığını korumak için alınabilecek en güvenilir ve en ucuz yöntem olan aşıya olumsuz bakış açısını değiştirmek için etkili önlemler alınması gerekmektedir. Çocuk aşılanmasına ilişkin olarak yapılan çalışmalarda, düşük aşılama oranlarının en çok bildirilen sebeplerinden biri, ebeveynlerin verilen bilgileri yetersiz bulması olmuştur. Bu konuda aileler uzman kişiler tarafindan yeterince bilgilendirilmeli, internet, televizyon ve gazetelerden olumlu bilgilendirme ve yayınlar yapılmalı (kamu spotu), iyi eğitilmiş sağlık personelleri sayesinde ebeveynlerin aşılara güvenmesinin sağlanması gerekmektedir. Andres ve ark. 2009 y1lında Madrid kentinde yaptıkları çalışmada, sağlı personelleri tarafindan yeterince bilgilendirildiklerine inananların aşılama oranları daha yüksek çıkmıştır Ayrıca devletin toplumun sağlığını korumak ve geliştirmek için her türlü önlemi alması gerekmektedir. Bu konuda gerektiğinde yasal yaptırımlar 
uygulanabilmelidir. Gardner ve ark. (2010), çalışmalarında aşı karşıtlığına gerekçe olarak politika yapıcılara olan güvensizlikte dikkat çekmektedir. Politika yapıcıların, aşılar konusunda sunulan bilgi ve desteği arttırmaları konuyla ilgili olumlu sonuçlar vereceği aşikârdır. Çocukların sağlık hakları yasalarla güvence altına alınmalıdır. Devlet yerli aşı üretimine geçerek aşıların içerikleri konusunda halkın kafasındaki soru işaretlerini giderebilmelidir.

\section{Kaynakça}

Allan, N. veHarden, J. (2014). ParentalDecision-Making İn Uptake Of The MMR Vaccination: A SystematicReview Of QualitativeLiterature. Journal Of Public Health,37(4): 678-687.

Altun, Ş. (2008). 6-14 Yaş Arası Çocuklarda Aşılanma Oranı ve Ailelerin Özel Aşılarla İlgili Bilgi Düzeyi. Bakırköy Dr. Sadi Konuk Eğitim ve Araştırma Hastanesi, Uzmanlık Tezi, İstanbul.

Ames, H.M., Glenton, C., ve Lewin, S. (2017). Parents' And Informal Caregivers' Views And Experiences Of Communication About Routine Childhood Vaccination: A Synthesis Of Qualitative Evidence. Cochrane Databaseof SystematicReviews. (2).

Ataç, Ö. ve Aker, A.(2014). Aş1 Karşıtlı̆̆ı. Sağlık Düşüncesi ve Tıp Kültürü Dergisi, 30: 42-47

Attwell, K., Smith, D. T., \&Ward, P. R. (2018). 'The Unhealthy Other': How Vaccine Rejecting Parents Construct The Vaccinating Mainstream. Vaccine, 36(12), 1621-1626.

Avcı E. (2017). Çocukluk Dönemi Aşılarına İliş̧kin Karşılaştırmalı Bir Analiz: Amerika Birleşik Devletleri ve Türkiye, Liberal Perspektif: Analiz, 9

Badur S. (2011). Aşı Karşıtı Gruplar ve Aşılara Karşı Yapılan Haksız Suçlamalar. ANKEM, 25(Ek 2): $82-86$

Başkale, H(2016). Nitel araştırmalarda geçerlik, güvenirlik ve örneklem büyüklüğünün belirlenmesi. Dokuz Eylül Üniversitesi Hemşirelik Fakültesi Elektronik Dergisi,9(1):23-27

Benin, A. L., Wisler-Scher, D. J., Colson, E., Shapiro, E. D., Holmboe, E. S. (2006). Qualitative Analysis Of Mothers' Decision-Making About Vaccines For İnfants: The İmportance Of Trust. Pediatrics, 117(5), 1532-1541.

Bernard, S., Enayati, A., Redwood, L., Roger, H., Binstock, T. (2001). Autism: A Novel Form Of Mercury Poisoning. Medical Hypotheses, 56(4), 462-471.

Bluhm, D. J., Harman, W., Lee, T. W., Mitchell, T. R. (2011). Qualitative Research İn Management: A Decade Of Progress. Journal Of Management Studies, 48(8), 1866-1891.

Bodemer, N., Muller, S.M., Okan, Y., Garcia-Retamero, R., Neumeyer-Gromen, A. (2012). DoThe Media Provide Transparent Health İnformation? A Cross-Cultural Comparison Of Public İnformation AboutThe HPV Vaccine. Vaccine,30: 3747-3756.

Boom, J. A. ve Cunningham, R. M. (2014). Understanding and managing vaccine concerns. Springer. http://immunizesa.com/images/Dr.JulieA.Boom-VaccinehesitancyandHPV.pdf Erişim tarihi:15.01.2019

Bozkurt, H. B. (2018). Aş1 Reddine Genel Bir Bakış ve Literatürün Gözden Geçirilmesi.Kafkas J MedSci, 8(1),71-76

Brandt, C., Rabenau, H. F., \&Wicker, S. (2011). Attitudes Of İnfluenza-Vaccinated Health Care Workers Toward Masks To Prevent Nosocomial Transmission Of İnfluenza. Influenza And Other Respiratory Viruses, 5(1), 61-66. 
Ailelerin Aşı Karşıtlığı Tutumlarının Hemşireler Tarafından Değerlendirilmesine Yönelik.... 1161

Bryden, G. M., Browne, M., Rockloff, M., Unsworth, C. (2017). Anti-vaccination and pro-CAM attitudes both reflect magical beliefs about health. Vaccine, 36: 1227-1234

Burghouts, J., Del Nogal, B., Uriepero, A., Hermans, P. W., De Waard, J. H.\&Verhagen, L. M. (2017). Childhood Vaccine Acceptance And Refusal Among Warao Amerindian Caregivers İn Venezuela; A Qualitative Approach. PlosOne, 12(1).

Carrasco-Garrido, P., de Andres, A.L., Hernandez-Barrera, V., Gil de Miguel, A., JimenezGarcia, R. (2009). Patient's perceptions and information provided by the public health service are predictors for influenza vaccine up take. Human Vaccines, 5: 839-842.

Casiday, R., Cresswell, T., Wilson D., Panter-Brick, C. (2006). A Survey Of UK Parental Attitudes To The MMR Vaccine And Trust İn Medical Authority. Vaccine, 24:177-184.

Çapanoğlu, E. (2018). Sağllk Çalışanı ve Ebeveyn Perspektifinden Çocukluk Çağı Aşılarının Reddi Niteliksel Bir Araştırma. Yayımlanmamış Yüksek Tezi, Acıbadem Mehmet Ali Aydınlar Üniversitesi Sağlık Bilimleri Enstitüsü, İstanbul.

Da SilvaFagundes, L. G., Frota, O. P.\&Silva, E. M. (2018). Nursing Practices İn Vaccination: An İntegrative Review. Journal Of Nursing Education And Practice, 8(8): 128-136

Davies, P., Chapman, S.\&Leask, J. (2002). Antivaccination Activists On The World Wide Web. Archives Of Disease In Childhood, 87(1):22-25.

Destefano, F. (2009). Thimerosal-Containing Vaccines: Evidence Versus Public Apprehension. Expert Opinion On Drug Safety, 8(1): 1-4.

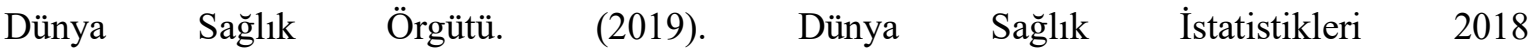
https://www.tuseb.gov.tr/enstitu/tacese/yuklemeler/istatistik/9789241565585_eng.pdf Erişim tarihi: 15.01.2019)

Evans, M., Stoddart, H., Condon, L., Freeman, E., Grizzell, M.\&Mullen, R. (2001). Parents' Perspectives On The MMR İmmunisation: A Focus Group Study. Br J Gen Pract ,51(472):904-10

Gardner, B.,Davies, A.,Mcateer, J.\&Michie, S. (2010). BeliefsUnderlying UK Parents' ViewsTowards MMR Promotionİnterventions: A QualitativeStudy. PsycholHealthMed, 15(2):220-30.

Gust, D. A., Kennedy, A., Shui, I., Smith, P. J., Nowak, G., \&Pickering, L. K. (2005). Parent Attitudes Toward İmmunizations And Healthcare Providers: The Role Of Information. American Journal Of Preventive Medicine, 29(2): 105-112.

Hausman, B. L., Ghebremichael, M., Hayek, P.\&Mack, E. (2014). 'Poisonous, Filthy, Loathsome, Damnable Stuff': The Rhetorical Ecology Of Vaccination Concern. The Yale Journal of Biology And Medicine, 87(4): 403.

Hilton, S., Petticrew, M.\&Hunt, K. (2007). Parents' Champions Vs. Vestedİnterests: Who Do Parents Believe About MMR? A QualitativeStudy. BMC Public Health, 7(1): 42.

Hornsey, J.M., Harris, E.A.\&Fielding, K.S. (2018). The Psychological Roots of Anti-Vaccination Attitudes: A 24-Nation Investigation. HealtPsychology, 37(4):307

http://apps.who.int/immunization_monitoring/globalsummary/countries?countrycriteria\%5Bcountr y\%5D\%5B\%5D=TUR Erişim tarihi:12.01.2019

http://www.hurriyet.com.tr/kelebek/saglik/ikiz-bebeklerineasi-yaptirmayan-savcinin-hukuk-zaferi29343111 Erişim tarihi: 12.01.2019 
http://www.who.int/mediacentre/factsheets/fs378/en/ ImmunizationcoverageFactsheet (Erişim tarihi: 11.01.2019)

https://www.who.int/news-room/fact-sheets/detail/immunization-coverage (Erişim tarihi: 12.01.2019)

Hurley, A.M., Tadrous, M.\&Miller, E.M. (2010). Thimerosal-Containing Vaccines And Autism: A Review Of Recent Epidemiologic Studies. J Pediatr Pharmacol Ther. 15(3): 173-181.

İslamoğlu, A.H, Alnıaçı, Ü. (2014). Sosyal Bilimlerde Nitel Araştırma Yöntemleri, İstanbul, Beta Yayıncilik. 205-222.

Jacobson, D. L., Gange, S. J., Rose, N. R.\&Graham, N. M. (1997). Epidemiology And Estimated Population Burden Of Selected Autoimmune Diseases İn The United States. Clinical Immunology And Immunopathology, 84(3): 223-243.

Kang, G. J., Ewing-Nelson, S. R., Mackey, L., Schlitt, J. T., Marathe, A., Abbas, K. M., \&Swarup, S. (2017). Semantic Network Analysis Of Vaccine Sentiment İn Online Social Media. Vaccine, 35(29): 3621-3638.

Kutlu, H. Ve Altındiş, M. (2018). Aş1 Karşıtlığı. Flora Dergisi, 23(2): 47-58.

Kürtüncü, M., Alkan, I., Bahadır, Ö., Arslan, N. (2017). Zonguldak'ın Kırsal Bir Bölgesinde Yaşayan Çocukların Aşılanma Durumu Hakkında Annelerin Bilgi Düzeyleri. Ejovoc (Electronic Journal Of VocationalColleges), 7(1): 8-17

Mckeever, T. M., Lewis, S. A., Smith, C.\&Hubbard, R. (2004). Vaccination And Allergic Disease: A Birth Cohort Study. American Journal Of Public Health, 94(6): 985-989.

Öncel, E. K., Büyükcam, A., Cengiz, A. B., Kara, A., Ceyhan, M., Doğan, B. G. (2015). Hekim ve Hemşire Dışındaki Hastane Personelinin Mevsimsel Grip Aşısı ile İlgili Bazı Bilgilerinin, Görüşlerinin ve Tutumlarının Değerlendirilmesi. Journal of PediatricInfection/Çocuk Enfeksiyon Dergisi, 9(2):68-75

Polat, H. H., Yalçin, A. N. Ve Öncel, S. (2010). Influenza Vaccination; Rates, Knowledge And The Attitudes Of Physicians İn A University Hospital. Turkiye Klin J MedSci, 30: 48-53.

$\begin{array}{llllll}\text { Sağlık } \quad \text { Bakanlığı. (2018). Sağlık İstatistikleri } & \text { Y1llı̆̆ } & 2016\end{array}$ https://dosyasb.saglik.gov.tr/Eklenti/13183,sy2016turkcepdf.pdf?0, Erişim tarihi: 11.01.2019

$\begin{array}{llllll}\text { Sağlık } \quad \text { Bakanlığı. (2019). Să̆lık İstatistikleri } & \text { Yıllığı } & 2017\end{array}$ https://dosyasb.saglik.gov.tr/Eklenti/28709,210119saglik-istatistikleri-yilligipdf.pdf?0 Erișim tarihi: 25.01 .2019

Seval, M. Ve Kocagöz Acar, G. (2018). Aşılanma ve Aşılanma ile Illgili Asılsız Mitler. 1.Uluslararası Sağlık Bilimleri Bilim ve Yaşam Kongresi Sunumu

Sevencan, F., Ertem, M., Özçullu, N., Dorman, V. Ve Kubat, N. K. (2011). The Evaluation Of The Opinions And Attitudes Of Healthcare Personnel Of The Province Diyarbakir Against İnfluenza A (H1N1) And The Vaccination. Human Vaccines, 7(9): 945-951.

Stefanoff, P., Mamelund, S.E\&RobinsonM. (2010). Tracking Parental Attitudes On Vaccination Across European Countries: The Vaccine Safety, Attitudes, Training And Communication Project (VACSATC). Vaccine, 28: 5731-5737.

Taylor, S., Khan, M., Muhammad, A., Akpala, O., Van Strien, M., Morry, C.\&Ogden, E. (2017). Understanding Vaccine Hesitancy İn Polio Eradication İn Northern Nigeria. Vaccine: 35(47), 6438-6443. 
Ailelerin Aşı Karşıtlığı Tutumlarının Hemşireler Tarafindan Değerlendirilmesine Yönelik.... 1163

UNICEF. (2011). Türkiye'de Çocukların Durumu Raporu
http://unicef.deparyazilim.com/files/bilgimerkezi/doc/sitan-tur-2011.pdf Erişim tarihi: 13.01.2019)

Wenger, O. K., Mcmanus, M. D., Bower, J. R.\&Langkamp, D. L. (2011). Underimmunization İn Ohio's Amish: Parental FearsAre A Greater Obstacle Than Access To Care. Pediatrics, Peds-2009.

WHO, UNICEF. (2009). World Bank. State Of The World's Vaccines And İmmunization, Geneva. World Health Organization, 130-145.

Wiley, K.E., Steffens, M, Berry, N.\&Leask, J. (2017) An Audit Of The Quality Of Online İmmunisation İnformation Available To Australian Parents. BMC Public Health,17(1): 76.

Yaqub, O., Castle-Clarke, S., Sevdalis, N.\&Chataway, J. (2014). Attitudes To Vaccination: A Critical Review. Social Science\&Medicine, 112: 1-11.

Yıldırım A., Şimşek H. (2016). Sosyal Bilimlerde Nitel Araştırma Yöntemleri, Ankara, Seçkin Yayınc1lik. 25-288

Yiğitalp, G. (2008). Diyarbakır İlinde 0-12 Aylık Çocukların Aşıya Devamsızlık Nedenleri. TAF Preventive Medicine Bulletin, 7(4): 277-284. 